\title{
Children, Asthma and Emergency Rooms: A Retrospective Review of Hospital Records in Nevis, West Indies E Jones, J Richardson
}

\begin{abstract}
Objectives: We sought to identify pediatric emergency room (ER) utilization at Alexandra Hospital Nevis, WI for asthma.

Methods: Our utilization study employed a retrospective randomized chart review of pediatric patients (0-10 years of age) between January $1^{\text {st }}, 2012$ and December $31^{\text {st }}$, 2014. Univariate, bivariate analysis and ArcGIS were employed to explain the distribution of asthmatic cases and to present potential sources of asthma triggers in parishes with a high representation of asthma. Results: Of the 383 randomized patients represented, 42 were asthmatic. Of the 640 ER presentations represented, 89 were asthmatic. Males (59/89 presentations or 66.3\%) and children $0-5$ years of age (71/89 presentations or $79.8 \%)$, represented a higher proportion of asthmatic cases. A greater number of asthmatic ER presentations occurred in the first calendar quarter of the year (34/89 presentations or $38.2 \%$ ). Of the records indicating a home parish, most asthmatic presentations represented St. John's or St. George's parishes $(67 / 85$ presentations or $78.8 \%)$. Of the distinct asthmatic patients, $26(n=42)$ were male; $31(n=42)$ were between the ages of 0-5 years of age; and 32 patients $(n=42)$ were from St John's or St. George's parishes. The overrepresentation of asthmatic patients and presentations from St John's and St. George's parishes coincide with drought severity assessment data.
\end{abstract}

Conclusions: We identified a greater utilization of ER services by particular subpopulations in our study. This information can be used for the appropriation of staff and resources, as well as designing interventions targeting these subpopulations to encourage more efficient utilization of community health clinics.

Keywords: Asthma, chart review, Nevis pediatric, public health surveillance

From: Dr E Jones, Department of Public Health Sciences, School of Medicine, University of Virginia, Charlottesville, Virginia, ${ }^{2}$ Jeanita W. Richardson. Department of Public Health Sciences, School of Medicine, University of Virginia, Charlottesville, Virginia.

Correspondence: Mr E Jones, Department of Public Health Sciences, School of Medicine University of Virginia, Charlottesville, Virginia, United States of America

Email: edj5jb@virginia.edu 


\section{INTRODUCTION}

Asthma has emerged as a significant global public health concern due to its increasing prevalence, its effect on quality of life, and the high cost of care associated with a late diagnosis $(1,2)$. In 2002, asthma replaced gastroenteritis as the most frequent diagnosis in Kittitian and Nevisian children.(3) While recognized as a significant health concern to this island Federation, many nations in the Caribbean exhibit similarly high rates of child hospitalizations due to asthma. Surveys of admissions to pediatric hospitals' emergency rooms (ER) throughout the Caribbean revealed that as many as $23 \%$ of admissions were visits from patients with asthmatic symptoms.(1) In the report, "Managing Asthma in the Caribbean" authors note, "Furthermore, population-based surveys of Caribbean adolescents report that over 13\% of participants admitted to having a past or present diagnosis of asthma."(1) Experts postulate that such high prevalence rates translate into high costs of care (1). As the Caribbean Health Research Council reported, “...the major contributory factors to asthma morbidity and mortality are an under-diagnosis and inappropriate or inadequate treatment."(1) Consequently, the Nevis Ministry of Health requested that researchers conduct a chart review of the medical records of pediatric patients who are treated at the Alexandra Hospital ER. The broader objective of this collaborative research is to determine if asthmatic patient utilization of the ER is aligned with the distribution of health care on the island.

Questions have been raised regarding the choices made by families and care-givers of asthmatic patients who under-utilize free community clinics, and seek more expensive and significantly less accessible care from hospital ERs.(2) The SKN government prides itself on its guiding principles of equal access, a focus on prevention, and affordability of health care to its citizens. Community clinics, which provide free or heavily subsidized care from the government, 
are imperative to the health system. Under-utilization of community clinics is of concern to the Ministry of Health because it is believed to have yielded greater costs associated with treating a significant proportion of pediatric asthma cases with services at ERs (2). There are seventeen free community clinics (eleven located on St. Kitts and six on Nevis), purposely located such that one exists in each parish, and that each household is located within three miles of a clinic [See Figure 1] (3).

Two publicly-funded hospitals exist in the Federation, with one located on each island (Joseph N Frances (JNF) on St. Kitts, and Alexandra Hospital on Nevis). Together, these hospitals provide 217 total hospital beds. With a 2014 population of 55,000 (and a projected population of 63,000 in 2030), little testimony is required to suggest the importance of community clinics as a critical component of the federation's health infrastructure, which contribute to the efficient provision of care for the country $(4,5,6)$.

Further review of existing literature contributed to evidence which described the role of improper perceptions, usage, and ultimately dependence on ER services. One qualitative study described the lived experiences of Puerto Rican families caring for their child's asthma by using the ER for treatment. Their findings suggested that caregivers of asthmatic children felt that the ER was where their child would receive the best care for their asthma. These families also felt that the number of services offered at the ER was greater than those offered at local clinics (7). Similar perceptions may exist in SKN, resulting in the over-utilization of hospital ERs and creating a burden to the health system as a whole. Likewise, other research in the management of pediatric asthma demonstrated that a shift in responsibility of asthma care practices from caregivers to youth is a variable, uneven, and complex process. This shift in asthma management has been identified to influence how well management practices translate into an individual's 
ability to manage asthma later in life (8-15). Therefore, proper use of health care on Nevis will contribute to a child's development of successful management practices when they become more independent. Another study of the Federation's health system investigated parental knowledge regarding child asthma triggers and health seeking behavior (2). It found that clinicians and parents alike shared the same level of knowledge pertaining to the severity of asthma and its triggers among SKN youth. With this knowledge, perceptions of asthma severity cannot be isolated as the key factor in the over-utilization of hospital ERs.

Proper use of ER services and greater utilization of the community clinics would provide a more efficient provision of services, impose less financial burden on individuals and on the health care system, and result in improved health outcomes for asthmatic children. This quantitative analysis of the prevalence and characteristics of pediatric asthma patient's presentations (or "visits") to the Alexandra ER provides concrete evidence of the pediatric asthma-related burden on one hospital in the SKN health system. This knowledge serves as a foundation with which to inform future health interventions, policies and research focused on Nevisian pediatric asthmatic patients' management of their asthma.

Methods:

We conducted a retrospective randomized chart review of ER medical records at Alexandra Hospital to provide a substantive representation of the pediatric patient population on Nevis, who depend on asthma therapy at the hospital.(16) To obtain the clinical information describing the presentations of this population, we required access to written medical records. After receiving HSR-IRB approval through the University of Virginia (\#18110), IRB approval from the St. Kitts and Nevis Ministry of Health, as well as signing a Patient Confidentiality Agreement, we were granted access to the medical records at the Alexandra Hospital ER. The 
various sources of medical records in the Alexandra ER, included: "New Cases Logs", "Daily Records Logs", and "Asthma Bay Logs" (each of which recorded different patients depending on the frequency and type of treatment received). These logs organized presentations treated in order of appearance by day. The presentations of all pediatric patients meeting our inclusion criteria from these logs were recorded into a spreadsheet.

Inclusion criteria required patients to be 0 to 10 years of age at the time of their presentation, and the presentation had to have occurred between January $1^{\text {st }}, 2012$ and December $31^{\text {st }}, 2014$. The ages of 0 to 10 years are the optimum age range, which would yield information on the parental-management strategies of caregivers, who often guide the decisions of pediatric patients. This time period was chosen based our ability to conduct a thorough analysis for a comprehensive timeframe that included complete data for each year reviewed.

The presentations of pediatric patients eligible for our study were recorded in a spreadsheet with the respective patient name and date of presentation documented. These lists averaged roughly 2,200 different presentations for each year reviewed. After these lists were alphabetized (priority set as: last name, first name) the multiple presentations for one patient were listed together, allowing for easy identification of a patient's presentation history for a complete year. A randomization method of selecting every $1 / 10^{\text {th }}$ distinct patient name was used for generating our samples. The patients selected for our samples, and each of their presentation dates, were then recorded on a form which contained a unique patient identifier number. This identifier number served as a crosswalk to be used on our chart review forms, allowing us to identify patients from our samples in the medical records. These cross-reference identifier assignment sheets were kept locked and separate from the data recorded on our chart review forms for the duration of the study. 
With our samples of the pediatric patient population at the Alexandra ER, each presentation of every patient selected was revisited in the medical records. The relevant clinical data for each presentation were recorded to determine the patient's chief-complaint and the treatment that they received. If the presentation was identified as asthmatic, all of the relevant information provided in the medical records was documented on our chart review forms. For presentations to the ER for any complaints not consistent with our definition of asthma, no more clinical information was recorded. Through consultation with nurses, EMTs, and physicians at Alexandra Hospital, the following criteria were selected to determine if presentations were asthmatic or not: patients chief complaint included "Wheezing" or "Difficulty Breathing" (or a related phrase), and treated with Atrovent, Prednisone, Ventolin Inhaler, Ventolin/Salbutamol Nebulizers, or Hydrocortisone Stats. These medications were validated by physicians, nurses, and EMTs at Alexandra Hospital as the available treatment options for the management of asthmatic symptoms in this age group. Our plans for statistical analysis included univariate and bivariate analysis of patient and presentation characteristics. ArcGIS Software was utilized to provide a geospatial analysis for our chart review data. Publically available shapefiles were accessed and converged with our findings to present potential sources of asthma triggers in parishes with a high representation of asthma in the Alexandra ER.

\section{RESULTS}

\section{Sample characteristics}

The samples for each of the years 2012, 2013, and 2014 are summarized in Table 1 . Nearly $11 \%$ of all patients from our three-year sample were asthmatic. Asthmatic representation among all 
presentations to the ER for the same three-year period was nearly $14 \%$. Likewise, greater than $64 \%$ of all asthmatic patients from our three samples were indicated in the records as a "Known Asthmatic".

\section{Stratified sampling and asthmatic representation}

Table 2 shows the prevalence of pediatric asthma found among the three years of data stratified by age strata, gender, reported home parish, and quarter of the year. Males accounted for a greater proportion of asthmatic patients and asthmatic presentations in each of the samples. Children in the age strata of 0-5 years of age represented a greater proportion of asthmatic cases in all three metrics: asthmatic patients, asthmatic presentations, and asthmatic presentations by "known asthmatics".

Figure 2 shows asthmatic prevalence, by parish, among the presentations of patients who indicated a home parish in the medical records review. Of the five parishes on Nevis, St. George and St. John parishes had the highest number of asthmatic patients and asthmatic presentations where a home parish was indicated in the medical records. The first calendar quarters of each year saw the greatest frequency in both the number of asthmatic patients and asthmatic presentations treated in the Alexandra ER.

Evidence of high utilization among certain patients was noted. As shown in Table 3, two patients each presented to the ER on ten occasions for the treatment of asthma in 2012. These patients together accounted for greater than $50 \%$ of all of the asthmatic presentations to the ER for our entire 2012 sample. Likewise, two patient IDs indicated among the most frequent asthma cases for 2013 and 2014 (ID\# 210088 and ID\# 200093), are for the same patient.

\section{Characteristics of medication prescribed}


Tables 4 and 5 show the frequencies and characteristics of medications and treatments prescribed for the management of asthmatic symptoms in this pediatric patient population. Ventolin or Salbutamol nebulizations are the most frequently provided therapy among all age strata and between both genders. A closer evaluation of the provision of nebulizations reveals significant differences in the number required to successfully manage symptoms in asthmatic patients. While there is little variation in the mode of nebulizations required among our samples, some records indicated patients who received up to four nebulizations in a single visit before their symptoms were managed and they were released from the ER.

\section{DISCUSSION}

The goal of this study was to provide the Ministry of Health with evidence to inform the current state of the provision and utilization of care for pediatric asthmatic patients, who present to the Alexandra Hospital ER. This is the first study to apply systematic chart review methods to quantify and evaluate asthmatic treatment within this patient population on Nevis. This study found evidence of a greater utilization of services offered at the Alexandra ER by pediatric asthma patients and their caregivers. Some subpopulations among our samples, such as males and children aged 0-5 years of age, represent a higher proportion of pediatric asthma patients and asthmatic presentations. Likewise, a greater proportion of these asthmatic patients and presentations are represented in the first calendar quarter of the year and by patients from the parishes of St. John and St. George.

Potential sources of asthma triggers in these highly represented parishes were explored using publically available shapefiles which describe recent drought assessment data. $(17,18)$ 
Noting Figure 3, the region surrounding St. John and St. George parishes was determined to have severe drought conditions. Compromised air quality due to airborne dust from road traffic in these regions with greater drought conditions represents a potential asthma trigger for youth. This may be particularly true surrounding residential areas and nearby schools, where youth spend much of their day. More in depth analysis of these shapefiles and the association between drought conditions and asthma severity is difficult due to the limited amount of publically available datasets on Nevis.

Our findings do however necessitate further research to investigate factors that negatively influence a child's ability to manage asthma symptoms (e.g. existing environmental triggers), and to conduct air quality assessments in these areas. Additionally, public perceptions of the care offered by community clinics and their perceived limited accessibility (e.g. hours of operation) must be considered. Negative perceptions of the care offered by community clinics may prevent caregivers from seeking a clinic's care rather than the ER. Influential factors in pediatric asthma patients' use of ER services include the perceptions, self-management strategies, and healthseeking behavior of their caregivers (particularly among children in the age strata of 0-5 years of age).

Children in this younger age range are likely unable to clearly articulate symptom severity to caregivers, therefore delaying crucial time for the patient. Consequently, exacerbated symptoms may lead them to seek care at the ER. Caregivers might benefit from educational information, or the use of tools such as an asthma action care plan, which would empower the caregiver to more clearly define what stages of symptom severity necessitate certain levels of care. Likewise, community educational sessions might aide caregivers in the use and maintenance of nebulizers owned in their own home. Alexandra hospital nurses and providers 
articulated that some households owned their own nebulizers, but sought treatment from the hospital when they were unable to use them or ran out of medication. Lastly, comparative chart review methods can be applied to the six community clinics located throughout Nevis to identify what proportion of their pediatric patient population seeks treatment for asthma.

We encountered several limitations during the implementation of this study. Extra efforts were required to clearly decipher information provided in the hand written records. The diversity in sources of medical records likewise complicated our collection of clinical information. These two limitations were mediated through regular consultation with nurse staff, EMTs, and physicians within the Alexandra ER. Additionally, cross referencing between these various medical record sources validated the information that was collected. We were not made aware of an additional source of medical records, "Pediatrician Logs", until late in the analysis phase of the research. These logs included patients who would have otherwise satisfied our inclusion criteria. However, with only one of two visiting pediatricians recording logs in a manner accessible to us, these logs would not have been appropriate for our review. We feel that our classification of asthma diagnoses for the purposes of this study was an accurate assumption, but it is possible that several cases were lost due to our definition and interpretations. Consequently, our estimates for the proportion of asthmatic cases among our pediatric samples are likely underestimates. Despite these limitations, we believe that we have created the most representative sample of this patient population to date. 


\section{CONCLUSIONS}

Having identified a greater utilization of ER services by particular portions of this population, health care providers and staff at Alexandra Hospital, along with the Ministry of Health, should determine whether or not the dependence on these services creates a burden on the nurses and staff within the Alexandra ER. If the demand for the treatment of pediatric asthma in the ER does create a burden on their capacity of care, then the Ministry of Health can use this information for the appropriation of staff and resources, as well as designing interventions targeting these subpopulations, to mediate the burden exhibited on the Alexandra ER.

\section{ACKNOWLEDGMENTS}

We extend our gratitude to Chief Medical Officer Dr. Patrick Martin, Permanent Secretary Slack-Liburd, Matron Pemberton, and the clinicians and staff at Alexandra Hospital for their hospitality, consultation, and support throughout our research. Finally, special thanks to the Center for Global Health for their financial and logistical support, as well as the UVa HSR-IRB and Department of Public Health Sciences for their consultation and guidance. No grant number is applicable. 


\section{REFERENCES}

1. Caribbean Health Research Council. Managing Asthma in the Caribbean [Internet]. St. Augustine, Trinidad and Tobago; 2009 [cited 2015 Jan 20]. Available from: http://carpha.org/Portals/0/docs/Clinical\%20Guidelines/Managing\%20Asthma\%20in\%20 the\%20Caribbean.pdf.

2. Moore S. When a Cough is not a Cold: Healthcare-seeking Behaviours of Asthmatic Children's Caretakers in Saint Kitts and Nevis [Master's Theses]. Charlottesville, VA: University of Virginia; 2014.

3. Pan-American Health Organization. Saint Kitts and Nevis [Internet]. Pan American Health Organization Website. 2007 [cited 2015 Jan 20]. Available from: http://ais.paho.org/hia_cp/en/2007/Saint\%20Kitts\%20and\%20Nevis\%20English.pdf?ua= 1.

4. St. Kitts and Nevis Ministry of Health, Pan American Health Organization, World Health Organization. Saint Kitts and Nevis Pharmaceutical Country Profile [Internet]. World Health Organization Website. 2012 Jun [cited 2015 Nov 1] Available from: http://www.who.int/medicines/areas/coordination/SaintKittsNevis_country_profile.pdf.

5. Snyder E, Martin M, Awosogba T, Brown D, Plummer B, Shawar Y. Culture of St. Kitts and Nevis. J Race and Policy. 2011 [cited Nov 27]; 7(1): 9-14.

6. The World Bank. Health, Nutrition and Population Statistics [Internet] Updated 2016 Apr [cited 2016 Feb 1] Available from:

http://databank.worldbank.org/data/reports.aspx?source=health-nutrition-and-populationstatistics\&preview=on. 
7. Coffey J, Cloutier M, Meadows-Oliver M, Terrazos C. Puerto Rican Families' Experiences of Asthma and Use of the Emergency Department of Asthma Care. J Pediatr Health Care [Internet]. 2011 Mar [cited 2015 Nov 27]; 26(5): 356-363. doi: 10.1016/j.pedhc.2011.01.006

8. Hafetz J, Miller V.A., Child and parent perceptions of monitoring in chronic illness management: a qualitative study. Child Care Health and Dev [Internet]. 2010 Sep [cited 2015 Nov 27]; 36(5): 655-662. doi: 10.1111/j.1365-2214.2010.01102.x

9. Garwick A, Seppelt A, Riesgraf M. Addressing Asthma Management Challenges in a Multisite, Urban Head Start Program. Public Health Nurs [Internet]. 2010 Jul-Aug [cited 2015 Dec 02]; 27(4): 329-336. doi: 10.1111/j.1525-1446.2010.00862.x

10. Martin M, Beebe J, Lopez L, Faux S. A Qualitative Exploration of Asthma SelfManagement Beliefs and Practices in Puerto Rican Families. J Health Care Poor Underserved [Internet]. 2010 May [cited 2015 Dec 02]; 21(2): 464-474. doi: 10.1353/hpu.0.0285

11. Walker V. Minority Caregivers' Emotional Responses and Perceptions of the Emotional Responses of their Children to Asthma: Comparing Boys and Girls. Issues Ment Health Nurs [Internet]. 2013 May 13 [cited 2015 Dec 10]; 34(5): 325-334. doi: $10.3109 / 01612840.2012 .753559$

12. Buford T. Transfer of Asthma Management Responsibility from Parents to their SchoolAge Children. J Pediatr Nurs [Internet]. 2004 Feb [cited 2015 Dec 08]; 19(1): 3-12. doi: 10.1016/j.pedn.2003.09.002 
13. Shu-Chen C, Yu-chih C, Yiing Mei L, Kai-Wei K, Pei-Fan M. Mothers' experience with 1st-3rd grade children with asthma assisting their child's adaption of school life in Taiwan. J Clin Nurs [Internet]. 2010 Jun 14 [cited 2015 Dec 08]; 19(13-14): 1960-1968. doi: 10.1111/j.1365-2702.2009.03137.x

14. Beacham B, Deatrick J. Children with Chronic Conditions: Perspectives on Condition Management. J Pediatr Nurs [Internet]. 2014 Nov 14 [cited 2015 Dec 18]; 30(1): 25-35. doi: 10.1016/j.pedn.2014.10.011.

15. Loignon C, Bedos C, Sevigny R, Leduc N. Understanding the self-care strategies of patients with asthma. Patient Educ Couns [Internet]. 2008 Nov 28 [cited 2016 Jan 3]; 75(2): 256-262. doi: 10.1016/j.pec.2008.10.008.

16. Vassar M, Holzmann M. The retrospective chart review: important methodological considerations. J Educ Eval Health Prof [Internet]. 2013 Nov 30 [cited 2015 Dec 17]; 10(12). doi: 10.3352/jeehp.2013.10.12.

17. Google My Maps. Map data @2016 Google Imagery @2016 TerraMetrics. Emergency Shelters, Police \& Health Centers of Nevis [Internet]. 2016 [cited 2015 Oct 07]. Available from: https://www.google.com/maps/d/u/1/viewer?mid=z0iLhjPGOM_s.kNSYckFpibEE\&hl=e n\&authuser $=1$.

18. Organization of American States (OAS.org). Post-Georges Disaster Mitigation (PDGM) GIS Data: Nevis Drought Risk [Internet]. 2001 Sep 10 [cited 2015 Oct 07]. Available from: http://www.oas.org/pgdm/data/gis_data.htm. 1:25,000 Scale. 
Table 1: Prevalence of pediatric asthmatic patients and asthmatic presentations

\begin{tabular}{cccccc}
\hline $\begin{array}{c}\text { Sample } \\
\text { Year }\end{array}$ & $\begin{array}{c}\text { ER } \\
\text { Patients }\end{array}$ & $\begin{array}{c}\text { ER } \\
\text { Presentations }\end{array}$ & $\begin{array}{c}\text { Asthmatic } \\
\text { Patients } \\
\text { N }(\%)\end{array}$ & $\begin{array}{c}\text { Asthmatic } \\
\text { Presentations } \\
\text { N }(\%)\end{array}$ & $\begin{array}{c}\text { "Known Asthmatic" } \\
\text { Patients } \\
\text { N }(\%)\end{array}$ \\
\hline 2012 & 131 & 234 & $11(08.39)$ & $39(16.67)$ & $11(100.00)$ \\
2013 & 120 & 199 & $16(13.33)$ & $24(12.06)$ & $8(50.00)$ \\
2014 & 132 & 207 & $15(11.36)$ & $26(12.56)$ & $8(53.33)$ \\
Total: & 383 & 640 & $42(10.97)$ & $89(13.90)$ & $27(64.29)$ \\
& & & & & \\
\hline
\end{tabular}

Table 2: Prevalence of pediatric asthmatic patients and asthmatic presentations, stratified by age strata, gender, home parish, and calendar quarter of the year

\begin{tabular}{|c|c|c|c|}
\hline Characteristics & $\begin{array}{l}\text { Asthmatic } \\
\text { Patients } \\
\text { N (\%) }\end{array}$ & $\begin{array}{c}\text { Asthmatic } \\
\text { Presentations } \\
\text { N (\%) }\end{array}$ & $\begin{array}{c}\text { Asthmatic Presentations by } \\
\text { "Known Asthmatics" } \\
\text { N (\%) }\end{array}$ \\
\hline \multicolumn{4}{|l|}{ Age (Years) } \\
\hline $0-5$ & $31(73.80)$ & $71(79.78)$ & $52(58.43)$ \\
\hline $6-10$ & $11(26.20)$ & $18(20.22)$ & $14(15.73)$ \\
\hline \multicolumn{4}{|l|}{ Gender (M/F) } \\
\hline $\mathrm{M}$ & $26(61.90)$ & $59(66.29)$ & $40(44.94)$ \\
\hline $\mathrm{F}$ & $16(38.10)$ & $30(33.71)$ & $24(26.96)$ \\
\hline \multicolumn{4}{|l|}{ Home Parish } \\
\hline St. George & $10(23.80)$ & $19(22.35)$ & $10(16.13)$ \\
\hline St. James & $1(02.38)$ & $5(05.88)$ & $5(08.06)$ \\
\hline St. John & $22(52.38)$ & $48(56.47)$ & $37(59.68)$ \\
\hline St. Paul & $4(09.52)$ & $4(04.70)$ & $3(04.83)$ \\
\hline St. Thomas & $5(11.90)$ & $9(10.60)$ & $7(11.30)$ \\
\hline \multicolumn{4}{|l|}{ Calendar Quarter } \\
\hline $1^{\text {st }}$ (Jan. - Mar.) & $22(36.67)$ & $34(38.20)$ & $25(39.06)$ \\
\hline $2^{\text {nd }}$ (Apr. - Jun.) & $14(23.33)$ & $17(19.10)$ & $8(12.50)$ \\
\hline $3^{\text {rd }}$ (Jul. - Sept.) & $14(23.33)$ & $22(24.72)$ & $18(28.13)$ \\
\hline $4^{\text {th }}$ (Oct. - Dec.) & $10(16.67)$ & $16(17.98)$ & $13(20.31)$ \\
\hline
\end{tabular}


Table 3: Frequency of asthmatic presentation by the three leading pediatric patients per year

\begin{tabular}{ccccc}
\hline Year & $\begin{array}{c}\text { Patient ID of } 3 \\
\text { Most Frequent } \\
\text { Asthmatics }\end{array}$ & $\begin{array}{c}\text { Number of } \\
\text { Asthmatic } \\
\text { Presentations }\end{array}$ & $\begin{array}{c}\text { \% of Total } \\
\text { Asthmatic } \\
\text { Presentations }\end{array}$ & $\begin{array}{c}\text { Cumulative \% of } \\
\text { Total Asthmatic } \\
\text { Presentations }\end{array}$ \\
\hline 2012 & 220009 & 10 & $25.64 \%$ & $64.10 \%$ \\
2013 & 220057 & 10 & $25.64 \%$ & \\
& 220071 & 5 & $12.82 \%$ & \\
2014 & $210088^{*}$ & 3 & $12.50 \%$ & $33.33 \%$ \\
& 210048 & 3 & $12.50 \%$ & \\
& 210024 & 2 & $8.33 \%$ & \\
& 200021 & 4 & $15.38 \%$ & $38.44 \%$ \\
& 200006 & 3 & $11.53 \%$ & \\
& $200093^{*}$ & 3 & $11.53 \%$ & \\
\hline
\end{tabular}

*Indicates the same patient throughout multiple sample years

Table 4: Medications prescribed during asthmatic presentations

\begin{tabular}{cccccc}
\hline $\begin{array}{c}\text { Asthmatic } \\
\begin{array}{c}\text { Presentations } \\
(\mathrm{N})\end{array}\end{array}$ & $\begin{array}{c}\text { Ventolin } \\
\text { Inhaler/Puffer } \\
(\mathrm{N})\end{array}$ & $\begin{array}{c}\text { Ventolin / } \\
\text { Salbutamol } \\
\text { Nebulization } \\
(\mathrm{N})\end{array}$ & $\begin{array}{c}\text { Atrovent } \\
(\mathrm{N})\end{array}$ & $\begin{array}{c}\text { Prednisone } \\
(\mathrm{N})\end{array}$ & $\begin{array}{c}\text { Hydrocortisone Stat } \\
(\mathrm{N})\end{array}$ \\
\hline 0-5 y.o. (71) & 21 & 68 & 9 & 1 & 11 \\
6-10 y.o. (18) & 8 & 16 & 1 & 0 & 2 \\
Males (59) & 16 & 56 & 8 & 1 & 13 \\
Females (30) & 13 & 29 & 2 & 0 & 0 \\
\hline
\end{tabular}


Table 5: Descriptive characteristics of nebulizations prescribed to asthmatic patients

\begin{tabular}{ccccc}
\hline $\begin{array}{c}\text { Population (N) } \\
\text { (Presentations) }\end{array}$ & $\begin{array}{c}\text { Treated with } \\
\text { Nebulizations } \\
\text { N (\%) }\end{array}$ & $\begin{array}{c}\text { Average Number } \\
\text { Per Visit }\end{array}$ & Range & Mode \\
\hline 0-5 y.o. (71) & $68(95.77)$ & 1.56 & $0-4$ times & 1 \\
6-10 y.o. (18) & $17(94.44)$ & 1.43 & $0-4$ times & 1 \\
Males (59) & $56(94.91)$ & 1.52 & $0-4$ times & 1 \\
Females (30) & $29(96.66)$ & 1.46 & $0-4$ times & 1 \\
\hline
\end{tabular}




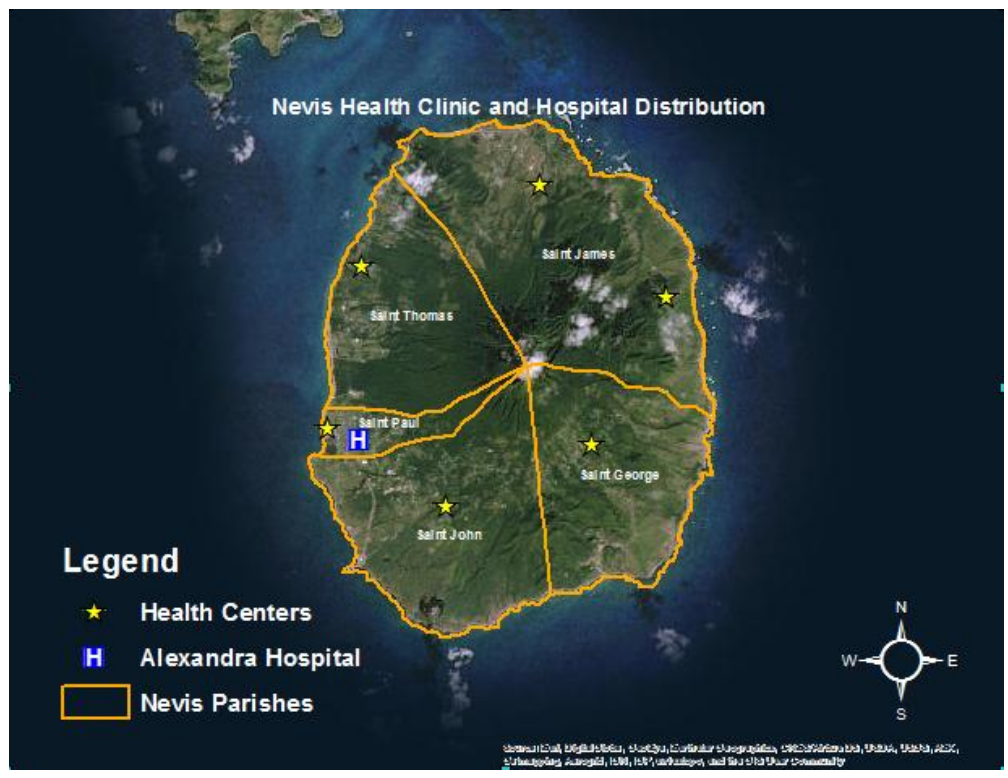

Fig 1: Nevis Health Clinic and Hospital Distribution (Produced using ArcGIS Software)

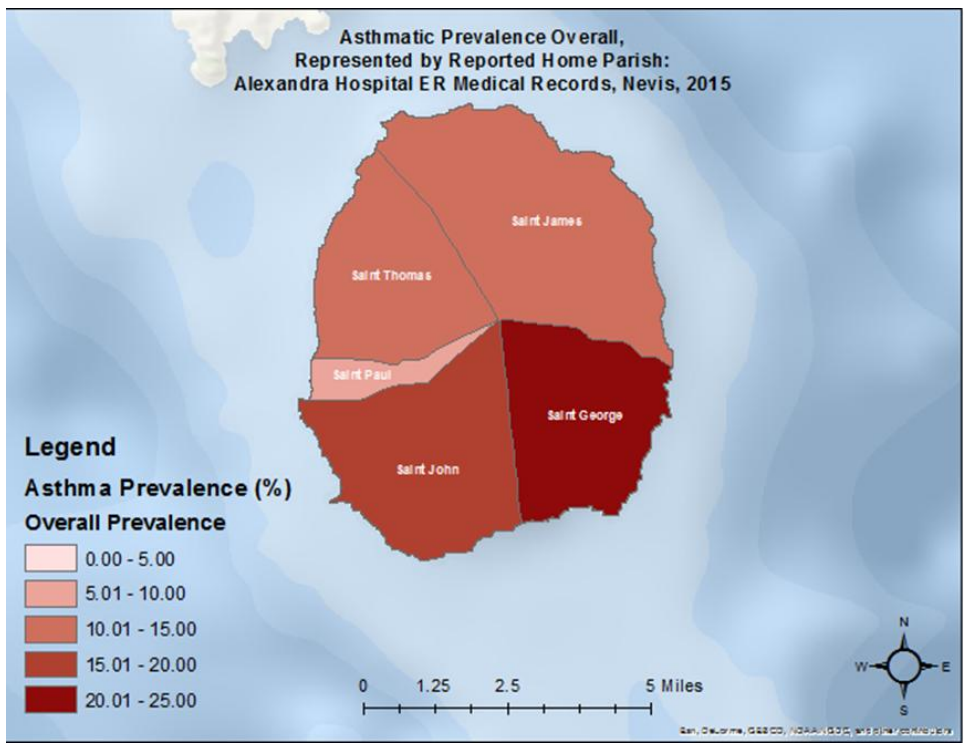

Fig 2: Distribution of asthmatic prevalence overall, by parish, among presentations to the alexandra hospital er (produced using arcgis software) 


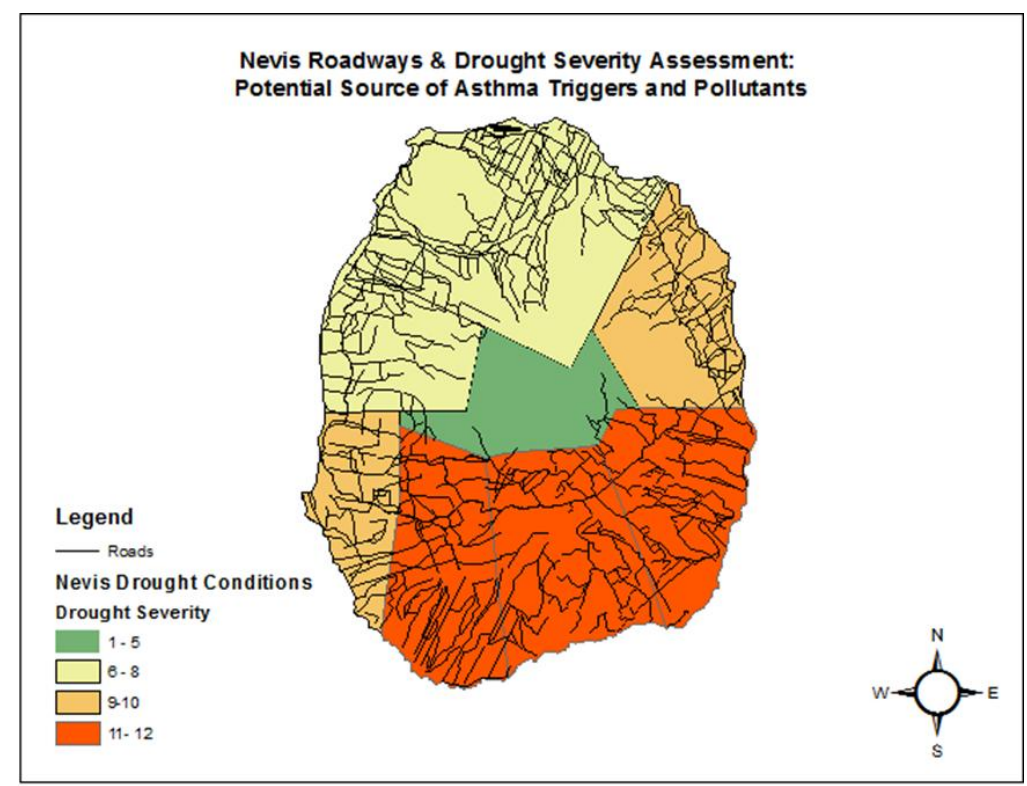

Fig 3: Nevis roadways and drought severity assessment map: potential source of asthma triggers and decreased air quality

Running head: Pediatric Asthma Surveillance at the Alexandra Hospital ER in Nevis, WI 